\title{
DEVELOPMENT AND VALIDATION OF A DISSOLUTION TEST FOR TELITHROMYCIN IN COATED TABLETS
}

\section{Lauren C. Vaucher*}

Departamento de Farmácia Industrial, Centro de Ciências da Saúde, Universidade Federal de Santa Maria, 97105-900 Santa Maria - RS, Brasil

Clésio S. Paim, Alini D. Lange e Elfrides E. S. Schapoval

Faculdade de Farmácia, Universidade Federal do Rio Grande do Sul, 90610-000 Porto Alegre - RS, Brasil

Recebido em 20/6/08; aceito em 14/1/09; publicado na web em 28/5/09

\begin{abstract}
A dissolution test for telithromycin tablets was validated and developed. In order to choose the most discriminatory one, the conditions to carry out are $900 \mathrm{~mL}$ of sodium phosphate buffer at $\mathrm{pH} 7.5$, paddles at $50 \mathrm{rpm}$ stirring speed, time test set to 60 min and using USP apparatus 2 with paddles. The UV spectrophotometric method for determination of telithromycin released was developed and validated. The method presents linearity $(r=1)$ in the concentration range of $20-60 \mu \mathrm{g} / \mathrm{mL}$. Precision and recoveries were good, 100.62 and $97.06 \%$, respectively. The method was successfully used for the dissolution test of telithromycin tablets.
\end{abstract}

Keywords: telithromycin; dissolution test; validation.

\section{INTRODUCTION}

In recent years, more emphasis has been placed on dissolution testing within the pharmaceutical industry and by regulatory authorities. ${ }^{1}$ The dissolution tests for immediate release solid oral dosage forms, such as tablets, are used to assess lot-to-lot quality of a drug product; guide development of new formulations and ensure continuing product quality and performance after certain changes, such as changes in the formulation, and the manufacturing process. ${ }^{2}$ From a biopharmaceutics point of view, a more discriminating dissolution method is preferred because the test will indicate possible changes in the quality of the product before in vivo performance is affected. ${ }^{3}$

Telithromycin, chemically [191114-48-4]3-De[(2,6-dideoxy-3$C$-methyl-11,12-dideoxy-6- $O$ - $\alpha$ Lribohexoppyranosyl)oxy]-methyl3-oxo-12,11-[ oxycarbonyl [ [4-[4-(3-pyridinil)-1H-imidazol-1-1-yl] butyl]imino]] erythromycin; $\mathrm{C}_{43} \mathrm{H}_{65} \mathrm{~N}_{5} \mathrm{O}_{10}$ (Figure 1); is the first antibiotic belonging to a new class of 14-membered ring macrolides, named ketolides, to achieve clinical use. ${ }^{4}$

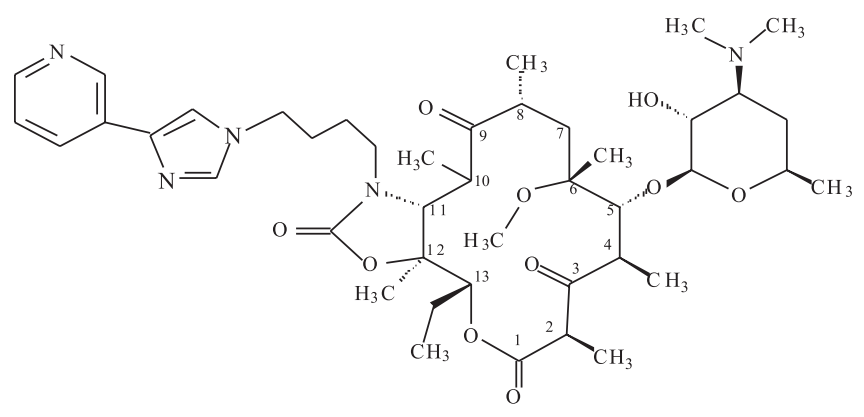

Figure 1. Chemical structure of telithromycin

The discovery of ketolides, derived from erythromycin incorporating a C-3 ketone modification, revealed a class of compounds with excellent activity against some macrolide-resistant bacteria, especially clinically important respiratory tract pathogens such as Streptococcus pneumonia. ${ }^{5}$

*e-mail: lauvau@terra.com.br
All macrolides structures and their ketolides-derivatives are based on a macrolactone ring. Telithromycin is structurally differentiated from the macrolides in three ways:The L-cladinose at the position $\mathrm{C} 3$ of the macrolactone ring has been replaced by a keto function, the $\mathrm{C} 6$ position was modified by the addition of a methoxy group avoiding the hemiketalization and the addition of a large aromatic $\mathrm{N}$-substituted carbamate extension at $\mathrm{C} 11 / \mathrm{C} 12$, each of which is associated with specific improvement in antimicrobial properties. ${ }^{4-6}$

Although there is a crescent number of works describing the determination of telithromycin in biological fluids ${ }^{7-10}$ but this drug in pharmaceutical formulation there is not listed in any pharmacopoeia and there is no dissolution test for this pharmaceutical dosage form reported in the literature. Due to this lack, our research group developed and published, in previous study, a microbiological assay in pharmaceutical dosage form applying cylinder- plate. ${ }^{11}$ A stability indicating assay by high-performance liquid chromatographic (HPLC) method was also developed and validated in our laboratory.

This way, the aim of this paper is to present the development and validation of dissolution test for telithromycin tablets that contain 400 $\mathrm{mg}$ of the drug and a UV spectrophotometric method for the quantitation of the drug from the dissolution test, as well as to evaluate the dissolution profile for tablets.

\section{EXPERIMENTAL}

\section{Materials}

The telithromycin reference standard (99.3\%) and the pharmaceutical dosage form were kindly supplied by Aventis Pharma (São Paulo, Brazil).

Telithromycin film-coated tablets were claimed to contain 400 $\mathrm{mg}$ (as the anhydrous base) of the drug and the following inactive ingredients: corn starch, croscarmellose cellulose, polyethylene glycol, povidone, red ferric oxide, talc, titanium dioxide, and yellow ferric oxide. All of the excipients were obtained from different local distributors.

Water was purified using Millipore ${ }^{\circledR}$ system. HPLC grade methanol, orthophosphoric acid (reagent grade) $\left(\right.$ Merck $^{\circledR}$ Darmstadt, Germany). Hydrochloric acid $(\mathrm{HCl})$, sodium hydroxide and sodium acetate were (Quimex $\left.{ }^{\circledR}\right)($ Merck, Brazil). Monobasic potassium phos- 
phate and sodium lauryl sulfate (SLS) (Synth $\left.{ }^{\circledR}\right)$ SãoPaulo, Brazil). Glacial acetic acid (Nuclear ${ }^{\circledR}$ Brazil). The 0.01 and $0.1 \mathrm{M} \mathrm{HCl}$, and sodium acetate USP buffer ( $\mathrm{pH} 4.0$ ), monobasic potassium phosphate USP buffer ( $\mathrm{pH} 6.8,7.5$ ) were prepared according to the directions in United States Pharmacopoeia. ${ }^{12}$

\section{Apparatus and conditions}

The dissolution test was performed in a Sotax AT7 multi-bath (n =6) dissolution test system (Basel, Switzerland), in accordance with USP 30 general methods. ${ }^{12}$ A liquid chromatograph (Shimadzu, Kyoto, Japan) equipped with a model LC-10ADvp binary pump, SIL- 10ADvp autosampler, CTO-10ACvp column oven, SPDM10Avp PDA detector, SCL-10Avp system controller and a Class - VP software was used to quantify the samples. UV detection was performed at $265 \mathrm{~nm}$. The stationary phase was an Ace RP-18 octadecyl silane column ( $250 \mathrm{~mm}$ x 4.6 $\mathrm{mm}$, particle size $5 \mu \mathrm{m})$. The column temperature was maintained at 50 ${ }^{\circ} \mathrm{C}$. The mobile phase was composed by methanol and $0.67 \mathrm{M}$ potassium monobasic phosphate buffer adjusted to $\mathrm{pH} 4.0$ with orthophosphoric acid $(55: 45 v / v)$. It was prepared daily, filtered through a $0.45 \mu \mathrm{m}$ membrane filter (Millipore) and degassed using the degasser of the chromatographic system prior to use. The flow rate of the mobile phase was $1 \mathrm{~mL} / \mathrm{min}$ and the injection volume was $20 \mu \mathrm{L}$. The retention time of the telithromycin chromatographic peak was observed at $6.3 \mathrm{~min} .{ }^{13}$

A UV-VIS Recording Spectrophotometer UV-160A (Shimadzu), using $1.0 \mathrm{~cm}$ quartz cells and SPECTRA MANAGER software was used for all absorbance measurements.

The Digimed potentiometer, model DM - 20 (São Paulo, Brazil), was used to determine the $\mathrm{pH}$ of all solutions.

The ultrasonic bath used for deaeration was the model USC 2850 (Unique, São Paulo, Brazil) and the $0.45 \mu$ m nylon membranes were Millx (Millipore, São Paulo, Brazil).

The filter used for mobile-phase filtration was the $\mathrm{MFS}^{\circledR} 0.45$ $\mu \mathrm{m}, 47 \mathrm{~mm}$, nylon membrane.

Sample filtration was carried out using as centrifuge the model excelsa 2, Fanem ${ }^{\circledR}$. The three filters evaluated for sample filtration were: Millipore ${ }^{\circledR} 0.45 \mu \mathrm{m}, 13 \mathrm{~mm}$, nylon membrane; Framex ${ }^{\circledR}$, quantitative filter, $10 \mathrm{~mm}$; Frama ${ }^{\circledR}$, qualitative filter, $3.0 \mu \mathrm{m}$.

\section{Dissolution tests conditions}

\section{Solubility determination and sink conditions}

Solubility data were used as the basis for the selection of a dissolution medium for telithromycin. Drug solubility was determined at 37 ${ }^{\circ} \mathrm{C}$ in different media and expressed as percentage of drug dissolved. The term sink conditions is defined as the volume of medium at least greater than three times that required to form a saturated solution of drug substance. ${ }^{3,14,15}$

The sink conditions were determined in different media: $\mathrm{HCl}$ $0.1 \mathrm{M}, \mathrm{HCl} 0.01 \mathrm{M}, \mathrm{HCl} 0.001 \mathrm{M}, \mathrm{H}_{2} \mathrm{O}, \mathrm{H}_{2} \mathrm{O}+0.5 \%$ sodium lauryl sulfate, phosphate buffers $\mathrm{pH} 6.8$ and 7.5 and acetate buffer $\mathrm{pH} 4.0$ were tested. Vessels $(n=3)$ containing $15 \mathrm{~mL}$ of medium were preheated to $37^{\circ} \mathrm{C}$ before adding an excess of telithromycin $(30 \mathrm{mg})$. The samples were gently rotated. An aliquot $(5 \mathrm{~mL})$ was removed from each vessel after 1 and $2 \mathrm{~h}$ and filtered. One milliliter of the filtered aliquots were pipetted, diluted with mobile phase at a final concentration the $50 \mu \mathrm{g} / \mathrm{mL}$ and injected into the LC. A LC method ${ }^{13}$ with UV detection, developed in our laboratory was select to get a solubility determination because of its ability to separate telithromycin from the degraded products. The LC method did not suffer interference by the formulation excipients and its degraded products, since no other peaks occurred in the same telithromycin retention time $\left(R_{t}=6.3\right.$ min), using the analytical conditions described above.

\section{Stability determination}

The solutions stability was analyzed over $12 \mathrm{~h}$ at room temperature. Sample solutions were prepared in all different dissolution medium at the same conditions by the dissolution test. Aliquots were collected in each hour diluted with mobile phase at a final concentration of $50 \mu \mathrm{g} / \mathrm{mL}$ and injected into the LC. A LC method ${ }^{13}$ with UV detection, developed in our laboratory was select to get a stability determination because of its ability to separate telithromycin from the degraded products.

\section{Filter evaluation}

The filter evaluation is necessary to determine if it could be used in the dissolution test without adsorption of the drug and that it removes insoluble excipients that may otherwise cause high background or turbidity. ${ }^{3}$

A standard and a sample solutions were prepared in different dissolution media proposed with a final concentration of $44.44 \mu \mathrm{g} /$ $\mathrm{mL}$. The sample solutions were prepared using a placebo added an amount of reference standard equivalent to $400 \mathrm{mg}$ of telithromycin in a beaker with $900 \mathrm{~mL}$ dissolution medium maintained at $37.0 \pm 0.5^{\circ} \mathrm{C}$ and stirred with a magnetic stirrer for $1 \mathrm{~h}$. Aliquots of $10 \mathrm{~mL}$ were withdrawn at the same point and each one was centrifuged, filtered with a quantitative filter, a $0.45 \mu \mathrm{m}$ nylon filter and a $3.0 \mu \mathrm{m}$ filter. The standard solutions were prepared in volumetric flasks and the final solution was analyzed without filtration and filtered with the same filters listed above. All the filtrates were analyzed by UV method. For a filter to be acceptable for use, the results of the filtered portions are to approach $(98-102 \%)$ the original concentrations of the unfiltered standard solution and the centrifuged sample solution. ${ }^{3,16}$

\section{Dissolution test and UV validation}

All dissolution medium were used to be tested in the drug release percent in order to choose the most discriminatory one. Dissolution testing was performed in compliance with USP $30^{12}$ using paddles (apparatus 2), $900 \mathrm{~mL}$ of the different dissolution medium. The medium, which was deaerated in the temperature of $48^{\circ} \mathrm{C}$ using an ultrasonic bath for $20 \mathrm{~min}$, was maintained at $37 \pm$ $0.5^{\circ} \mathrm{C}$. Manual sampling aliquots of $15 \mathrm{~mL}$ were withdrawn at 5 , $10,15,20,30,45$ and $60 \mathrm{~min}$. The replacement of the same volume of the medium at $37 \pm 0.5^{\circ} \mathrm{C}$ was done for constant maintenance of the volume. The standard solution, used in all dissolution tests, was prepared using an amount of powder equivalent to $11.11 \mathrm{mg}$ of telithromycin that was transferred to a $50 \mathrm{~mL}$ volumetric flask with the dissolution medium $(222.2 \mu \mathrm{g} / \mathrm{mL})$. Aliquot of $5 \mathrm{~mL}$ of this standard solution was transferred to a $25 \mathrm{~mL}$ volumetric flask and diluted with the same diluents obtaining the final concentration of $44.44 \mu \mathrm{g} / \mathrm{mL}$. The solution was filtered in quantitative filter, before analysis.

After choice of best conditions, the validation of the spectrophotometric method was performed. The UV method was selected because the excipients do not interfere with the maximum absorption of the drug and according to the literature ${ }^{3}$ it is the preferred method of analysis because results can be obtained faster, the analysis is simpler and fewer solvents are used. The ultraviolet spectrum for telithromycin standard is shown in Figure 2. Spectra obtained in phosphate buffers $\mathrm{pH} 7.5$ demonstrated a maximum absorbance at $263 \mathrm{~nm}$ and it was chosen as wavelength in the dissolution test analysis.

In order to demonstrate whether the method was adequate for dissolution test purposes, it was validated through the analysis of specificity, linearity, precision and accuracy parameters. ${ }^{2,12}$ 


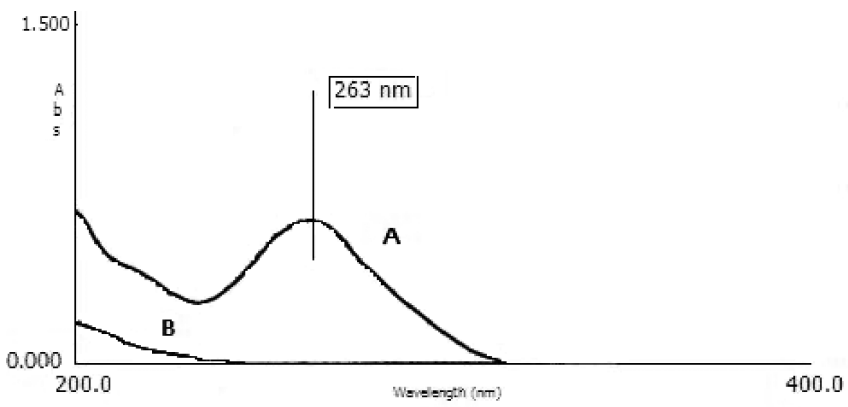

Figure 2. UV spectrum of telithromycin reference standard (a) and placebo (b) to the dissolution test with phosphate buffer $\mathrm{pH} 7.5$ at $37^{\circ} \mathrm{C}$ and apparatus 2 rotating $50 \mathrm{rpm}$

\section{Specificity}

It was evaluated by preparing a placebo sample of the reference commercial formulation of tablets in their usual concentration. The placebo sample was transferred to vessels with $900 \mathrm{~mL}$ of all different dissolution medium deaerated and stirred at $37{ }^{\circ} \mathrm{C}$ for $1 \mathrm{~h}$ at $150 \mathrm{rpm}$ using paddle (USP apparatus 2). ${ }^{3}$ Aliquots of this solution were filtered with quantitative filter and analyzed by UV spectrophotometric method.

\section{Linearity}

Appropriate amounts of telithromycin stock solution $(500 \mu \mathrm{g} / \mathrm{mL})$ prepared in methanol were diluted with phosphate buffer $\mathrm{pH} 7.5$ to give concentrations of 20.0, 30.0, 40.0, 50.0 and $60.0 \mu \mathrm{g} / \mathrm{mL}$. Each solution was prepared in triplicate. The linearity was evaluated by linear regression analysis, which was calculated by the least square regression method and analysis of variance (ANOVA).

\section{Precision}

Repeatability and intermediate precision were used to assess the precision of the method. Repeatability was evaluated through relative standard deviation (RSD) from the recovery data at $100 \%$ level. ${ }^{3}$

The intermediate precision (inter-day) was evaluated by comparing the assays on two different days and using different analyst. The RSD was determinate. The recovery data were performed, in triplicate, using a well-characterized lot of the drug product of tight content uniformity. The dissolution test was done for $60 \mathrm{~min}$ using $900 \mathrm{~mL}$ of dissolution medium phosphate buffer $\mathrm{pH} 7.5$, apparatus 2 rotating at $50 \mathrm{rpm}$.

Aliquots of $15 \mathrm{~mL}$ were filtered with quantitative filter and analyzed by UV spectrophotometric method at the same concentration ( $44.44 \mu \mathrm{g} / \mathrm{mL})$, under the same conditions, during the same day and in two different days respectively. Each concentration was prepared in duplicate and each one was analyzed in triplicate.

\section{Accuracy}

A recovery study was collected by adding known amounts of telithromycin reference substance to placebo solution at 80,100 and $120 \%$ of the nominal assay of telithromycin. The dissolution test was done for $60 \mathrm{~min}$ using $900 \mathrm{~mL}$ of dissolution medium phosphate buffer $\mathrm{pH} 7,5$, apparatus 2 rotating at $50 \mathrm{rpm}$. Aliquots of $15 \mathrm{~mL}$ were filtered with quantitative filter and analyzed by UV spectrophotometric method at the final concentration 35.56, 44.44, $53.33 \mu \mathrm{g} /$ $\mathrm{mL}$ respectively. Each concentration was prepared in duplicate and each one was analyzed in triplicate.

\section{RESULTS AND DISCUSSION}

The discriminatory power of the dissolution method depends on the method ability to detect changes in the drug product. Drug solu- bility and solution stability are important properties to be considered when selecting the dissolution medium. ${ }^{3}$

The sink conditions tested showed that telithromycin bulk was soluble in all the mediums tested except the water, therefore dissolution test for telithromycin tablets was performed using this dissolution medium at the stirring speed of $50 \mathrm{rpm}$, to investigate the drug release in each media.

The solubility in the aqueous media with $0.5 \%$ sodium lauryl sulfate was determined in order to improve the solubility in the aqueous media and then to get the most discriminatory medium. The surfactant may be used to enhance drug solubility. ${ }^{14}$

The initial parameters for filtration and solution stability must be established prior to the completion of any dissolution samples. ${ }^{17}$ The evaluation of the filters demonstrated that the quantitative and 0.45 $\mu$ m nylon filters were within $98-102 \%$ of the initial values and could be used in the dissolution tests in the different dissolution medium.

To evaluate the telithromycin stability a dissolution media were used, which were over the $\mathrm{pH}$ range of 1.0 to 7.5. This range is recommended as support and validation of dissolution tests. ${ }^{2}$ The chromatograms for each medium were obtained. According to the literature, the acceptable range for solution stability is $98-102 \%$ of the initial value. ${ }^{16}$

The specificity analysis revealed the UV method did not suffer interference by the formulation excipients. The results obtained suggested that the UV method could be used for telithromycin tablets quantitation in dissolution tests, once the formulation excipients didn't have significative absorbance (interference exceeds $2 \%$ of the reference absorbance) at $263 \mathrm{~nm}$ (Figure 2). Thus, the UV method is useful to quantify telithromycin in pharmaceutical formulation from the dissolution tests.

The dissolution test conditions were selected based on a screening study with USP apparatus 2 (50 rpm paddles). According to USP ${ }^{12}$ paddles is normally used to dissolution test of tablets. The tablets were tested in $900 \mathrm{~mL}$ of $\mathrm{HCl} 0.1 \mathrm{M}, \mathrm{HCl} 0.01 \mathrm{M}, \mathrm{HCl} 0.001 \mathrm{M}$, $\mathrm{H}_{2} \mathrm{O}, \mathrm{H}_{2} \mathrm{O}+0.5 \%$ sodium lauryl sulfate, phosphate buffers $\mathrm{pH} 6.8$ and 7.5 and acetate buffer $\mathrm{pH} 4.0$ (Figure $3 \mathrm{a}$ ).

The aqueous media with $0.5 \%$ sodium lauryl sulfate demonstrated a fast drug release and the results for RSD showed higher.

Telithromycin showed high solubility and the drug product had demonstrated a rapidly dissolving in all the tested mediums except in the aqueous medium. According the literature ${ }^{2,3,14}$ rapidly dissolving drug product is defined as one for which no less than $85 \%$ of the label claim is dissolved within $30 \mathrm{~min}$, as tested using USP apparatus 2 at $50 \mathrm{rpm}$ and that this products needs not be subject to a profile comparison if they can shown to release $85 \%$ or more of the active drug substance within $15 \mathrm{~min}$. For these types of products a one-point test will suffice. However the aim of our work was obtained the best conditions to development a discriminatory method, in this way when we used phosphate buffer pH 7.5 as the dissolution medium, the drug release in earlier time points was slower.

Therefore, this dissolution test condition using phosphate buffer pH 7.5 was selected because it allows maximum discriminating power and the drug release profile obtained in the developed dissolution test was considered the most satisfactory and discriminative (Figure 3b).

The solutions remained stable in all dissolution media tested for the time period specified and no degradation products were observed in any chromatogram. So, it was possible to guarantee the integrity of the drug during all the analysis time.

It was not done the comparison of dissolution profiles between products, once there is only one telithromycin brand in the Brazilian market. 

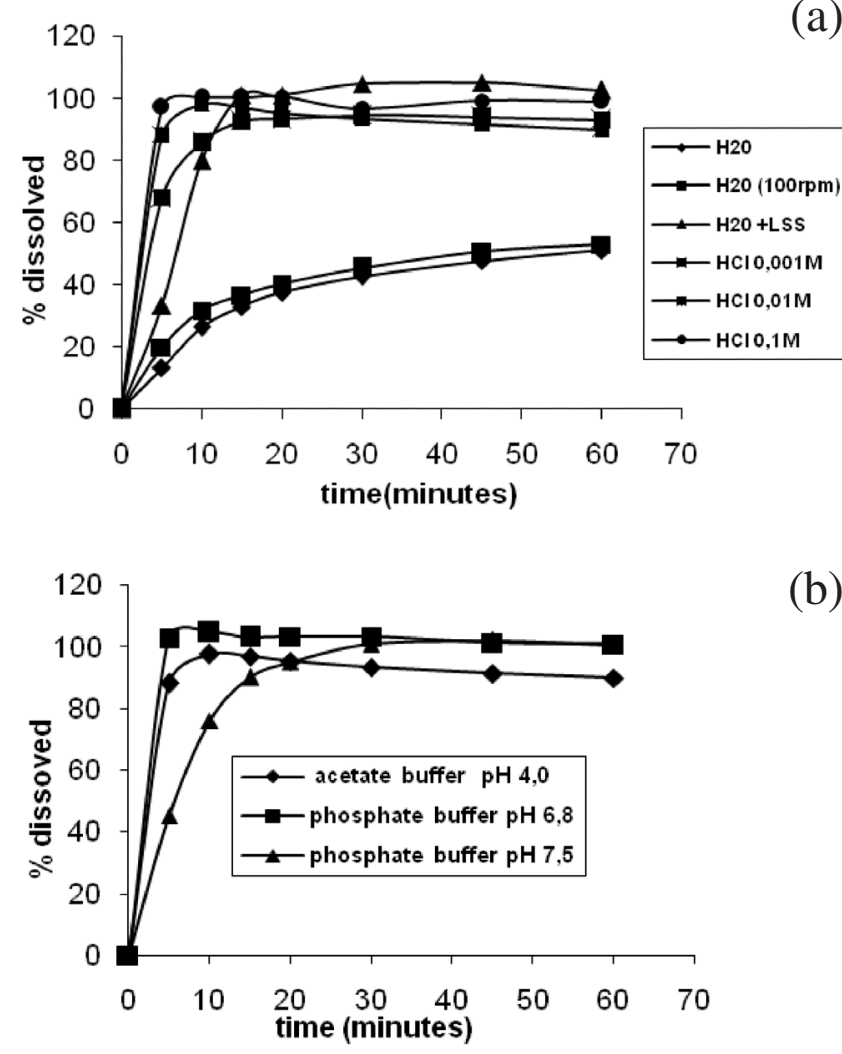

Figure 3. Dissolution profiles of telithromycin tablets using $\mathrm{H}_{2} \mathrm{O}, \mathrm{H}_{2} \mathrm{O}+\mathrm{SLS}$, $0,001 \mathrm{M} \mathrm{HCl}, 0,01 \mathrm{M} \mathrm{HCl}, 0,1 \mathrm{M} \mathrm{HCl}($ a), acetate buffer $\mathrm{pH}$ 4.0, phosphate buffer $\mathrm{pH} 6.8$ and $7.5(\mathrm{~b})$ in apparatus 2, rotating $50 \mathrm{rpm}$

To assess the linearity, three standard curves for telithromycin were constructed, plotting concentration $(\mu \mathrm{g} / \mathrm{mL})$ versus absorbance (ABS) and showed good linearity in the range of $20.0-60.0 \mu \mathrm{g} / \mathrm{mL}$ range, with a correlation coefficient of 1.0. The slope obtained was 0.0138 and the intercept was 0.0017 . The analysis of variance (ANOVA) showed significant linear regression and no significant linearity deviation $(\mathrm{P}<0.05) .{ }^{18}$ These data indicate that the method is linear for telithromycin with the specifications. ${ }^{18}$ The precision of the dissolution tests was evaluated through repeatability and intermediate precision. The repeatability demonstrated RSD for each day analyzed and the RSD for intermediate precision were in accordance with the data in the literature (1.6\% in the first day and $1.0 \%$ in the second day after 60 min). According to Pharmacopeial Forum ${ }^{3}$ the RSD is above $20 \%$ in time points at $10 \mathrm{~min}$ or earlier, and at or above $10 \% \mathrm{RSD}$ in later time points. These results can demonstrate the good precision of the method for dissolution test. These values are presented in Table 1.

The accuracy expresses the agreement between the accepted value and the value found. According to Marques, ${ }^{16}$ the recovery must to be in the range of $95-105 \%$ of thereference standard weight. The recovery found was in the range of $95.70-98.20 \%$ for telithromycin. The accuracy of the method was considered acceptable based on its intended use. These dates are given in Table 2.

The comparison of different dissolution mediums allowed us to define the test conditions as follows: $900 \mathrm{~mL}$ of phosphate buffer $\mathrm{pH} 7.5$ at $37^{\circ} \mathrm{C}$ as dissolution medium, paddle as apparatus at the stirring speed of $50 \mathrm{rpm}$ because our aim was select a discriminating dissolution method. The primary goal for the Dissolution Scientist is the development of a discriminating method, which must the ability to detect small changes in the formulation or manufacturing processes. ${ }^{17}$
Table 1. Intra and inter-day precision for the telithromycin sample using the UV spectrophotometric method

\begin{tabular}{lccc}
\hline \multicolumn{2}{c}{$\begin{array}{c}\text { Precision, } \\
\text { Intra-day }\end{array}$} & $\begin{array}{c}\text { Precision, } \\
\text { Inter-day }\end{array}$ \\
Time (min) & $\begin{array}{c}1^{\text {st }} \text { day } \\
{\text { (\%dissolved }{ }^{\text {nd }} \text { day }}^{(\mathrm{RSD})}\end{array}$ & $\begin{array}{c}\text { \%dissolved*) } \\
(\mathrm{RSD})\end{array}$ & $\mathrm{RSD}$ \\
\hline 5 & $45.07 / 14.4$ & $42.19 / 13.5$ & 0.7 \\
10 & $75.93 / 5.2$ & $72.39 / 4.4$ & 0.7 \\
15 & $90.12 / 2$. & $89.24 / 4.2$ & 0.8 \\
20 & $95.02 / 0.6$ & $96.20 / 1.3$ & 1.2 \\
30 & $100.89 / 1.1$ & $99.90 / 2.1$ & 1.0 \\
45 & $101.98 / 1.7$ & $100.25 / 2.1$ & 1.7 \\
60 & $100.40 / 1.6$ & $100.85 / 1.0$ & 0.4 \\
\hline
\end{tabular}

* each value is the mean of 3 determinations

Table 2. Accuracy results for telithromycin (\% recovery)

\begin{tabular}{lcccc}
\hline $\begin{array}{l}\text { Added } \\
(\mu \mathrm{g})\end{array}$ & $\begin{array}{c}\text { Recovered* } \\
(\mu \mathrm{g})\end{array}$ & $\begin{array}{c}\text { Recovery } \\
(\%)\end{array}$ & $\begin{array}{c}\text { Mean } \\
(\%)\end{array}$ & RSD \\
\hline $35.56(80 \%)$ & 34.92 & 98.20 & & \\
$44.44(100 \%)$ & 42.53 & 95.70 & 97.06 & 1.1 \\
$53.33(120 \%)$ & 51.89 & 97.30 & & \\
\hline
\end{tabular}

* each value is the mean of 3 determinations

\section{CONCLUSIONS}

The dissolution test developed and validated for telithromycin tablets was considered satisfactory. It was carefully studied in order to guarantee the drug stability during all the analysis time. We concluded, in this study, that if we want to use the most discriminating conditions for dissolution testing of telithromycin tablets, a phosphate buffer $\mathrm{pH} 7.5$ media, paddles and stirring speed of $50 \mathrm{rpm}$ should be us, appear to be the best condition.

The spectrometric method had been the traditional analytical method for dissolution test because the analyses are simpler; the results can be obtained faster. It was validated and showed to be specific, linear, precise and accurate.

The method demonstrated to be adequate to be used in quality control of telithromycin tablets since there is not a dissolution test indicated in official monograph, collaborating to the official codes.

\section{REFERENCES}

1. O'Hara, T.; Dunne, A.; Butler, J.; Devane, J.; Pharm. Sci. Technol. Today 1998, $1,214$.

2. FDA; Guidance for Industry: Dissolution Testing of Immediate Release Solid Oral Dosage Forms, 1997, Food and Drug Administration: Rockville, vol. 1, p. 17.

3. The United States Pharmacopoeia; Pharmacopeial Forum 2004, $30,351$.

4. The Merck Index, an Encyclopedia of Chemicals, Drugs, and Biologicals, Merck \& Co., INC: Whitehouse Station, New Jersey, 2001.

5. Hunter, P. A.; Drug Discov. Today 1998, 3,257. 
6. Zhanel, G. G.;Walters, M.; Noreddin, A.; Vercaigne, L. M.; Wierzbowski, A.; Embil, J. M.; Gin, A. S.; Douthwaite, S.; Hoban, R.; Drugs 2002, 62, 1711.

7. Perret, C.; Weinling, E.; Wessels, D. H.; Scholtz, H. E.; Montay, G.; Sultan, E.; Chemotherapy 2002, 48, 217.

8. Traunmuller, F.; Gattringer, R.; Zeitlinger, A.; Graninger, W.; Muller, M.; Joukhadasr, C.; J. Chromatogr., B: Anal. Technol. Biomed. Life Sci. 2005, 822, 133.

9. Khair, O.; Andrews, A.; Honeybourne, J. M.; Jevons, D.; Vacheron, G.; Wise, R.; Chemotherapy 2001, 47, 837.

10. Lingerfelt, B.; Champney, W. S.; J. Pharm. Biomed. Anal. 1999, 20, 459.

11. Vaucher, L. C.; Breier, A. R.; Schapoval, E. S.; J. AOAC Int. 2006, 89, 1398.
12. The United States Pharmacopeia, $30^{\text {th }}$ ed., Unites States Pharmacopeial Convention: Rockville, 2007.

13. Vaucher, L. C.; Paim, C. S.; Lange, A. D.; Schapoval, E. S.; Int. J. Pharm. 2009, 366, 82.

14. Brown, C. K.; Chokshi, H. P.; Nickerson, B.; Reed, R. A.; Rohrs, B. R.; Shah, P. A.; Pharm. Technol. 2004, 28, 56.

15. Rohrs, B. R.; Dissol. Technol. 2001, 8, 1.

16. Marques, M. R. C.; Brown, W.; Analytica 2002, 1,48.

17. Fortunato, D.; Dissol. Technol. 2005, 12, 12.

18. Farmacopéia Brasileira, $4^{a}$ ed., Atheneu: Rio de Janeiro, 1998. 